\title{
The Positive Side of Negative Interactions: Anxious and Avoidant Attachment as Moderators
}

\author{
Megan Parmenter, MA \\ Adelphi University, Garden City, New York, United States \\ (iD) https://orcid.org/0000-0002-2346-5148 \\ Katherine Fiori, $\mathrm{PhD}$ \\ Adelphi University, Garden City, New York, United States \\ (iD) https://orcid.org/0000-0003-3386-5898
}

Contact: meganparmenter@mail.adelphi.edu

\begin{abstract}
Although research has historically focused on the positive aspects of social ties, relationships inevitably involve a combination of positive as well as negative interactions. For the present study, we conducted a series of hierarchical linear regressions using longitudinal data from 108 first-year college students to test whether attachment anxiety and avoidance acted as moderators of the association between positive and negative social exchanges (assessed with the PANSE; Newsom et al., 2005) and changes in life satisfaction across the first year of college. We found that for individuals high on attachment avoidance or attachment anxiety, negative social exchanges were associated with increases in life satisfaction. In addition, whereas positive exchanges were associated with increases in life satisfaction among participants low on attachment avoidance, they were associated with decreases in life satisfaction among participants high on avoidance. Follow-up analyses using the subscales of the PANSE revealed the specific types of positive and negative exchanges driving these associations. Our findings highlight the relevance of attachment for understanding the role of social exchanges during the college transition.
\end{abstract}

Keywords: negative social exchanges; positive social exchanges; life satisfaction; attachment; moderation; college students

Date Submitted: July 9, 2020 | Date Published: January 18, 2021

\section{Recommended Citation}

Parmenter, M., \& Fiori, K. (2021). The positive side of negative interactions: Anxious and avoidant attachment as moderators. Journal of Social, Behavioral, and Health Sciences, 15, 1-30. https://doi.org/10.5590/JSBHS.2021.15.1.01

\section{Introduction}

The view that social relationships and supportive interactions are important to health and well-being has been shared across a wide range of disciplines, including psychology, medicine, sociology, public health, epidemiology, and education (Chu et al., 2010; Cohen, 2004; Holt-Lunstad et al., 2010; Uchino, 2006; Umberson \& Montez, 2010; Willis \& Ainette, 2012). In fact, during the COVID-19 pandemic, the World Health Organization recommended that the term "social distancing" be changed to "physical distancing" to emphasize the importance of maintaining personal relationships (Kaur, 2020). This is reflective of the fact 
that social isolation is linked to poorer psychological and physical health outcomes, as well as all-cause mortality, morbidity, and quality of life (Reblin \& Uchino, 2008).

Research has historically focused on the positive aspects of interpersonal relationships while overlooking the problematic aspects (Rook, 1984; Schuster et al., 1990). As such, the term "social support" is a commonly used and well-known term that is the focus of much of our literature review below. However, relationships inevitably involve a combination of positive (supportive) as well as negative (strained) interactions (i.e., exchanges). In the present study, we focus on "social exchanges" that better encompass both the positive and negative aspects of interpersonal relationships. In fact, an emerging body of research is beginning to examine positive and negative social exchanges as independent domains of social experience that differentially predict psychological well-being (Cheng et al., 2011). Yet these studies are limited by using measures of exchanges that are not parallel in nature, by relying on cross-sectional data, by failing to measure positive affect (Newsom et al., 2003), and by primarily sampling from older adult populations (e.g., Liu \& Rook, 2013; Newsom et al., 2005).

Inconsistent findings from studies on the benefits of support (i.e., supportive exchanges), as well as the risks associated with negative exchanges, imply that there may be individual differences in how social exchanges are experienced. The present study addressed these gaps by using parallel measures of positive and negative social exchanges (i.e., supportive and strained social interactions) to predict positive aspects of mental health (i.e., life satisfaction) in a sample of first-year college students and by evaluating attachment as a possible moderator of these associations. In addition, we selected a sample of first-year college students because the transition to college can be a particularly challenging time, during which social interactions may play a prominent role (Chemers et al., 2001). Finally, we examined the moderating effects of attachment, as individual differences may exist in how secure versus insecure students perceive and are affected by social exchanges during their first year of college.

\section{Theoretical Framework}

Given the transdisciplinary interest in the relationship between social support and positive health outcomes, it is necessary to clarify language to avoid conceptual ambiguity. First, as mentioned above, "social support" is a well-known term that most commonly refers to "a social network's provision of psychological and material resources intended to benefit an individual's ability to cope with stress" (Cohen, 2004, p. 676, italics in original). This definition is based on stress-buffering theory, which is an extension of the general stress and coping theory (Lazarus, 1966; Lazarus \& Folkman, 1984). Stress-buffering theory suggests that social support may act as an effective buffer against life stress by enhancing one's ability to cope (Cohen \& Willis, 1985).

Despite theoretical support for the "buffering hypothesis," inconsistencies in empirical research have resulted in findings that are generally inconclusive (Lakey \& Cronin, 2008; LaRocco et al.,1980). For example, Ingersoll-Dayton and colleagues (1997) found that, although positive social exchanges buffered against emotional distress stemming from stressful life events and negative social exchanges contributed to greater emotional distress, this was only found for older individuals (not middle-aged adults).

Although it is clear that social support can buffer against stress, it is important to examine potential direct effects between social support and mental health as well, particularly in a younger, college-aged sample. Attending college is a transitional event that is often associated with increased life stress (Thoits, 1995) as well as interpersonal development (Moller et al., 2003). As students separate from friends and family and adjust to new environments with various academic and social demands (Compas et al.,1986; Dyson \& Renk, 2006), they must formulate new assumptions about themselves and their future, as well as establish new social support systems to replace the support previously provided by family and high school friends (Hannum \& Dvorak, 2004). According to research, continued parental attachment and social support are two constructs that are integral to the college transition process (Coble et al., 1996; Holmbeck \& Wandrei, 1993). As a result, 
many undergraduate institutions provide social support programs to incoming students with the goal of enhancing success and decreasing vulnerability across the transition to college (Friedlander et al., 2007; Pratt et al., 2000; Rayle \& Chung, 2007). Despite the effectiveness of these interventions, Mattanah and colleagues (2010) found that the main effects were moderated by pre-college adjustment concerns. This suggests that not all students view the transition to college as equally stressful and individual differences exist in students' receptivity to programs designed to provide support. However, because that particular study relied on volunteers for the interventions, the authors were unable to determine if differences (e.g., in attachment) existed between students who were willing to participate in a social support group and those who were not.

College offers a new context in which students can try different activities and identities, as well as form new interests and friendships (Oswald \& Clark, 2003). These relationships appear to have generally beneficial effects on health, not solely or even primarily attributable to their buffering effects (House et al., 1988). Relational regulation theory provides a broad perspective to understand these main effects by suggesting that individuals are able to regulate their affect, thought, and action through ordinary conversations and shared activities (Lakey \& Orehek, 2011). For example, research shows that when a close other responds to good news in a constructive manner, the discloser experiences personal benefits, including decreased loneliness and increased positive emotions, psychological well-being, and esteem (Gable \& Reis, 2010).

\section{Social Exchanges and Well-Being}

Supportive social exchanges are often differentiated into three categories: instrumental support, informational support, and emotional support (Cohen, 2004). Instrumental and informational support are forms of tangible aid. Instrumental support involves the provision of material assistance (e.g., offering help with daily tasks), and informational support refers to the provision of relevant information (e.g., advice giving) intended to help the individual cope with current life difficulties. In contrast, emotional support involves showing empathy, compassion, and genuine concern. Emotional support is often provided by a close or intimate other and can be employed in direct (e.g., gift giving) or invisible ways (e.g., using a calm tone, listening empathetically; Howland \& Simpson, 2010). As mentioned earlier, although the term "support" is commonly used in the literature, this support must be exchanged; i.e., it requires interactions with network partners. Hence, instrumental, informational, and emotional support can also be understood as instrumental, informational, and emotional supportive exchanges. Companionship is a fourth category of supportive exchanges that has not been consistently included in studies but may make important contributions to wellbeing by providing a context for day-to-day enjoyment through pleasurable activities (Newsom et al., 2005).

The literature indicates that there are differences in the relative importance of each type of supportive exchange in terms of psychological health (e.g., Malecki \& Demaray, 2003; Morelli et al., 2015; Newsom \& Schulz, 1996; Oxman et al., 1992). Although emotional support is found to be more beneficial during uncontrollable stressors, instrumental and informational supportive exchanges may be more beneficial for relatively controllable forms of stress (Uchino, 2009; although instrumental support has also been positively linked to depressive symptoms in individuals with chronic illnesses; Penninx et al.,1998). These divergent findings may be due in part to whether measures assess appraisals/perceptions of supportive exchanges versus actual enacted support (Birditt et al., 2012).

Whereas enacted support is defined as the reported receipt of support resources, usually during a specific time frame (e.g., accepting reassurance during a time of stress), perceived support is defined as potential access to such supportive exchanges (Uchino, 2009). Consistent with stress-buffering theory, enacted support likely works indirectly on mental health by buffering or exacerbating life stress (Cohen \& Wills, 1985), whereas perceived support, in line with relational regulation theory (Lakey \& Orehek, 2011), may more directly influence mental health. Not only are enacted and perceived support distinct constructs, with an estimated link at $r=.35$ (Finch et al., 1999; Haber et al., 2007), but perceived support is found to be more strongly associated with mental health than enacted support or structural measures of support (i.e., number of social 
ties) (Lakey et al., 2010). In the present study, we focused on perceived supportive exchanges given their stronger direct link to mental health (i.e., life satisfaction) and our theoretical focus on relational regulation theory.

Because the term "social support" implies something favorable, the preceding theoretical and operational definitions can be misleading. Clearly, not all social exchanges are positive (Lincoln, 2000). Antonucci (1985) enumerates this by stating that "support which is intended by the provider to be positive, may be negative either because the objective outcome of the support provided is negative or the recipient of the support perceives the support negatively" (p. 29). This highlights the importance of appraisals and suggests that interactions can be either intentionally harmful, unintentionally harmful, or beneficial but perceived as harmful (e.g., being confronted about a risky behavior). For example, even when the support is well intended and responsive to an existing need, it can trigger feelings of dependency and indebtedness (Newsom et al., 2005). Because "negative social support" is not a commonly used term (in part because it sounds counterintuitive), researchers interested in the negative aspects of social relationships often focus instead on positive and negative social exchanges. As mentioned above, we take a similar approach in the present study and distinguish between specific domains of positive (supportive) and negative (strained) social exchanges (see Measures section).

Several reviews have shown that positive and negative exchanges appear to be relatively distinct constructs, meaning that negativity cannot be assumed in the absence of positivity (Finch et al., 1999; Rook, 1998). Although measures of positive social exchanges often have distinguished among different kinds of support (e.g., informational, instrumental, and emotional support; Finch et al., 1999), measures of negative social exchanges have seldom been explicitly multidimensional (Newsom et al., 2005). However, research suggests that both positive and negative social exchanges are multidimensional (Fiori et al., 2012) and that when comparing positive and negative social exchanges it is important to have symmetry in terms of the measures (e.g., dimensions, intensity) and in the time frame assessed (e.g., over the past month; Bertera, 2005). To overcome these issues, in the present study we relied on the Positive and Negative Social Exchanges measure (PANSE; Newsom et al., 2005). This scale investigates negative exchanges (involving others' unwanted advice or intrusion, others' unsympathetic or insensitive behavior, and others' failure to provide needed help; Newsom et al., 2003) that correspond to prominent categories of positive exchanges.

The PANSE also adds a fourth domain of both positive and negative exchanges, specifically companionship and its negative counterpart-rejection or neglect by others (Newsom et al., 2003). Companionship has not been systematically included in studies, perhaps because stress-buffering theory has neglected more expressive aspects of social interactions (Lawton et al., 1985; Rook, 1987). However, by providing opportunities for shared leisure and other activities that are undertaken primarily for the intrinsic goal of enjoyment, companionship may be appraised more positively and may exhibit stronger associations with wellbeing than other types of social support (Newsom et al., 2005). Similarly, being excluded from companionship (through rejection or neglect) may exhibit stronger associations with distress. Furthermore, companionship may capture some of the "direct effects" of social support outlined by relational regulation theory (Lakey \& Orehek, 2011).

In sum, the PANSE is designed to assess overall perceptions of network exchanges (i.e., participants are prompted to think in general about "the people in their lives," such as their partners, family members, friends, neighbors, or others), allowing for a complete impression of the extent to which broad positive and negative social exchanges interact to predict mental health (e.g., Fiori et al., 2012). Although many empirical studies have examined global dimensions of social network involvement, such as the impact of network size, frequency of interaction, and access to support on mental health (Rook, 2001), there are several advantages to taking a more nuanced approach. For example, there is evidence that positive and negative exchanges have different implications for different mental health outcomes (Fiori \& Consedine, 2013), suggesting the 
importance of the quality of interactions. Schuster and colleagues (1990) found that the absence of negative social exchanges may be more important for mental health (e.g., depressed mood) than the presence of supportive interactions. Moreover, the presence of negative social exchanges may be more potent than the beneficial effects of positive exchanges (Okun \& Keith, 1998), a phenomenon sometimes referred to as the "negativity effect" (Newsom et al., 2005). In line with this model, considerable research shows that negative ties are related to well-being more consistently than positive ties (Ingersoll-Dayton et al., 1997).

\section{The Moderating Role of Attachment Styles}

Many studies on the benefits of support (and the risks of negative interactions) focus on the differential effects of various relationships (e.g., parents, friends, or romantic partner) or types of support (e.g., emotional, instrumental, informational) for the entire population under examination, without attending to individual differences (Scholte et al., 2001). Research that has examined such individual differences has tended to focus on sociodemographic variables (Fiori et al., 2012; Pagel et al., 1987; Rook, 1984). For example, Fiori and colleagues (2012) found that positive exchanges reduced the negative association between negative exchanges and well-being for younger adults, but not for older adults, and for women, but not for men. Although gender, age, and other sociodemographic constructs seem to account for at least some variability in the association between social relationships and well-being, more proximal psychosocial constructs (Berkman et al., 2000), such as attachment styles, may be more clinically relevant.

Attachment has traditionally been defined as a strong affectional bond between the infant and primary caregiver (Bowlby, 1973, 1980), but has been extended to include all significant relationships across the lifespan (Blain et al., 1993). Whereas parents are the primary attachment figure in childhood and relationship partners (e.g., spouses) are the primary attachment figure in adulthood, multiple partners serve important attachment functions for younger adults (e.g., ages 18 to 25; Guarnieri et al., 2015). Moreover, striking a balance between autonomy (with parents) and relatedness (with key social partners) is an important developmental task (Shulman et al., 2003) and indicator of both attachment security and subjective wellbeing (Ma \& Huebner, 2008; Nickerson \& Nagle, 2005; Wei et al., 2011). Therefore, young adult attachment styles may be particularly salient for understanding links between social exchanges and well-being given that attachment is closely related to individuals' behaviors (e.g., disclosure, initiation), emotions (e.g., happy, relaxed, anxious, rejected), and perceptions (e.g., self-other perceptions) in social relationships.

Attachment styles in young adulthood can be conceptualized using a two-dimensional approach in terms of avoidance of intimacy and anxiety over abandonment (e.g., Miller, 2007). Individuals who are on the lower end of both dimensions are described as more securely attached. Securely attached individuals report positive models of self and others and believe that others are available to provide support when needed (Leiter et al., 2015). In other words, security of attachment is theoretically and empirically associated with perceptions of available social support (Moller et al., 2003). Unlike their securely attached counterparts, insecurely attached individuals report a negative model of self and/or others (Blain et al., 1993). Specifically, individuals higher on attachment anxiety tend to have a negative view of the self as well as a compulsive need to be close to others (Mikulincer \& Florian, 1995). Because they see themselves as unworthy, they may fear loss of social support, such as through abandonment by important attachment figures (West et al., 1986). By contrast, individuals higher on attachment avoidance typically have negative views of others. They are compulsively self-reliant and do not want to depend on others or have others depend on them (Miller, 2007). The preference for keeping a safe emotional distance is motivated by their negative self-views and distrust of others (Mikulincer \& Florian, 1995). This perpetuates their existing beliefs about the availability of and need for supportive relationships (Miller, 2007).

Not surprisingly then, securely attached individuals tend to find their interactions to be more rewarding, intimate, and emotionally positive (Kafetsios \& Nezlek, 2002). In addition, they are more likely to seek support during times of need (Collins \& Feeney, 2000; Herzberg et al., 1999), perceive others as being more 
responsive to their needs (Kafetsios \& Nezlek, 2002) and, in turn, be more satisfied with their support network (Priel \& Shamai, 1995). The opposite is true for insecurely attached individuals. In fact, Collins and Feeney (2004) found that avoidant and anxious individuals who received low-support notes from their partners prior to a speech performance task appraised the notes more negatively, rated their partner as being less supportive during a previous interaction, and performed significantly worse than secure participants. Insecure individuals who received genuine-support notes also perceived their partners as being less supportive during the task, which suggests that they may be predisposed to view others as less helpful and well intended (Collins \& Feeney, 2004). More generally, whereas securely attached individuals tend to perceive the highest levels of social support from friends, insecurely attached individuals (anxious and avoidant) perceive the lowest levels of social support (Anders \& Tucker, 2000; Davis et al., 1998; Florian et al., 1995; Ognibene \& Collins, 1998; Priel \& Shamai, 1995).

\section{The Current Study: Aims and Hypotheses}

Although attachment and social support have been linked conceptually and empirically (Kafetsios \& Sideridis, 2006), it remains unclear how different attachment dimensions moderate the association between different types of social exchanges and subjective well-being. This may be due in part to the fact that attachment and social support continue to be examined separately in the literature (Moller et al., 2003), without attending to the joint contributions of these distinct concepts during stressful periods, such as transitioning to college. To our knowledge, this is the first study to examine attachment as a moderator of the association between social exchanges and life satisfaction.

Examining attachment patterns in college students is particularly relevant as they are confronted with leaving home for the first time, developing new relationships, attempting challenging coursework, and exploring self and identity in a context of a changing social and academic environment (Kenny \& Rice, 1995). The longitudinal design of this study is a further improvement over past cross-sectional research as it allows for covarying initial levels of psychological health. We selected life satisfaction as our outcome measure because it is one of the most well-established measures of subjective well-being (Diener et al., 1985) and is associated with both gratifying social contacts (Oh et al., 2014) and academic success (e.g., grade point average; Cotton et al., 2002; Suldo et al., 2006). Hence, promoting college students' life satisfaction is an important outcome in itself, but it is also important to academic and professional success.

First, we hypothesized that positive exchanges would be positively associated, and negative exchanges negatively associated with changes in life satisfaction. Second, we hypothesized that anxious attachment would moderate the association between social exchanges and changes in life satisfaction. Given that the "negativity effect" (Ingersoll-Dayton et al., 1997) may be more pronounced in anxiously attached individuals who are hyperreactive to rejection, we hypothesized that the negative link between negative social exchanges and life satisfaction would be stronger among those high on anxious attachment. In contrast, we expected the positive association between positive social exchanges and life satisfaction to be weaker among individuals with high levels of anxious attachment. Third, we hypothesized that avoidant attachment would moderate the association between social exchanges and changes in life satisfaction. However, we did not make specific predictions about the direction of effects; although individuals high in avoidance often steer clear of emotional closeness in relationships and do not seek support from their partners during a crisis (Bartholomew, 1990), it is unclear how frequent positive or negative social exchanges would be associated with their life satisfaction. Finally, as an additional exploratory analysis, we investigated the interaction of anxious and avoidant attachment with each of the dimensions of social exchanges in predicting changes in life satisfaction to determine if any significant findings were being driven by particular types of positive or negative exchanges. 
Parmenter \& Fiori, 2021

\section{Method}

\section{Participants}

This study utilized data previously collected as part of a larger longitudinal study on changes in social networks across important life transitions (Fiori \& Consedine, 2013). Although the first wave of data included 305 individuals, only participants with information at both waves were included in the present study, for a final sample size of 108. Participants were college students enrolled at a medium-sized, private university in the northeast United States. Inclusion criteria were that participants had to be first-year students. Transfer students $(n=4,3.7 \%)$ were included if they met criteria for being first-year students at both phases of data collection. The final sample included participants with a mean age at Time 1 of $M=17.81(S D=0.41)$. Of them, $68 \%$ were single $(n=74)$ and $85 \%$ were female $(n=92)$. In all, $67 \%$ identified as White, $8 \%$ as African American, $11 \%$ as Asian, $6 \%$ as Hispanic, and $8 \%$ "Other." The majority of students $(n=69,64 \%)$ lived at home with their parents and commuted to campus, and the remainder $(n=39,36 \%)$ lived on campus. The median household income was $\$ 105,200$.

\section{Procedure and Design}

Data for the present study came from the first and second waves of a longitudinal study. Data were collected from September 2010 to May 2011. After Ethics Board approval, all first-year students were invited to participate in the study via first-year seminars, and those who agreed were given the same set of surveys. Time 1 survey data were collected from 305 first-year students (a 39\% response rate) at the beginning of the fall semester (September/October 2010). The survey was advertised via email and handed out in paper-andpencil format in freshman seminars. Surveys were completed outside of class and placed in a locked drop-box or collected by the researcher at the start of the next class. Students who consented to complete the follow-up survey provided their names and email addresses. If students did not consent to complete the follow-up survey, then no additional information was collected.

Time 2 data were collected at the end of the first year (April/May 2011) via an online survey from 113 freshmen (a 37\% response rate from the original sample). Five participants from this sample were excluded because they did not meet the criteria of being a first-year college student at Time 2. Thus, only the 108 individuals who completed the survey at follow-up and met eligibility criteria were included in the present analysis. Participants were entered into a drawing for a \$25 or \$50 Amazon gift card at Time 1 and a \$50 or $\$ 100$ Amazon gift card at Time 2.

\section{Sample Attrition}

Before our primary analyses, we investigated whether the college students who completed the follow-up survey differed from those who did not. Age, gender, race, attachment anxiety, attachment avoidance, and Time 1 positive and negative social exchanges were not significantly related to whether the participant completed the second survey. There were differences in residency (on campus or off campus) and life satisfaction. Specifically, students who responded at Time 2 were significantly more likely to live at home at Time $1(\chi 2=9.35, p<.01)$ and had higher levels of life satisfaction at Time $1(M=24.67, S D=6.04$ compared to $M=22.88, S D=6.66, t(290)=-2.31, p<.05)$.

\section{Measures}

\section{Social exchanges}

The PANSE Scale (Newsom et al., 2005) is a 24-item measure that assesses four domains of positive and four domains of negative social exchanges. The PANSE is frequently used in research assessing social exchanges and well-being in older adults and is validated for use in adolescent populations (Newsom et al., 2005). The 
four positive domains are informational support (e.g., make useful suggestions), instrumental support (e.g., do favors and other things for you), emotional support (e.g., cheer you up or help you feel better), and companionship (e.g., provide you with good company and companionship). The four negative domains are unwanted advice or intrusion (e.g., give you unwanted advice), failure to provide help (e.g., fail to give you assistance that you were counting on), unsympathetic or insensitive behavior (e.g., do things that were thoughtless or inconsiderate), and rejection or neglect (e.g., forget or ignore you). Participants were asked to consider the people in their lives (family members, friends, co-workers, community members, or others) and how often various exchanges had occurred over the past month. For example, "in the past month, how often did the people you know make useful suggestions" (positive exchange) or "give you unwanted advice" (negative exchange). The scale responses ranged from o (never) to 4 (very often). Total scores were obtained for positive and negative exchanges by calculating mean responses for each subscale, with a total score ranging from o to 4. Higher scores represented greater levels of positive or negative social exchanges. Cronbach's alpha for the positive exchanges subscale was .91 at Time 1. Cronbach's alpha for the negative exchanges subscale was .84 at Time 1 .

\section{Attachment style}

The Experiences in Close Relationships-Revised scale (ECR-R; Fraley et al., 2000) is a 36-item measure that consists of 18 items related to attachment anxiety (e.g., "I worry that others won't care about me as much as I care about them") and 18 items related to attachment avoidance (e.g., "I am nervous when my partner gets too close to me"). The ECR (1998) and the ECR-R (2000) are two of the most commonly used measures of adult attachment (Fraley et al., 2011). Compared to similar measures (e.g., Bartholomew \& Horowitz's Relationship Questionnaire, 1991), the ECR-R is considered more reliable and precise (Sibley et al., 2005) and is validated for use in adolescents and young adult populations (Wilkinson, 2011). In contrast to categorical models of attachment, continuous models of attachment (like the ECR-R) are more consistent at revealing individual differences (Fraley et al., 2015).

In order to assess attachment dimensions in multiple contexts, the original prompt ("The statements below concern how you feel in emotionally intimate relationships. We are interested in how you generally experience relationships, not just in what is happening in a current relationship. Respond to each statement by circling a number to indicate how much you agree or disagree with the statement") was modified so that participants responded to 18 items about general relationship attachment and 18 items about attachment to a romantic partner, a very close friend, or family member. The author of the scale indicated that the prompt can be modified for research purposes and applied to a variety of relational targets (Fraley, 2012).

Participants were asked at Time 1 only to respond to these items on a 7-point scale from 1 (strongly disagree) to 7 (strongly agree). Total scores were obtained for attachment anxiety and attachment avoidance by calculating mean responses for each subscale, with a total score ranging from 1 to 7 . Higher scores indicated a greater level of attachment avoidance or attachment anxiety. These variables were normally distributed. Cronbach's alpha for anxiety at Time 1 was .89 , and Cronbach's alpha for avoidance was .84 .

\section{Life satisfaction}

The Satisfaction with Life Scale (SWLS; Diener et al., 1985) is a short, five-item scale of global life satisfaction that is well-suited for use with a wide range of age groups (e.g., "In most ways my life is close to ideal"; "The conditions of my life are excellent"; "I am satisfied with my life"; "So far I have gotten the important things I want in life"; "If I could live my life over, I would change almost nothing"). Participants were asked (at both time points) to consider their level of agreement on a seven-point scale from 1 (strongly disagree) to 7 (strongly agree). Total scores were obtained by summing the items, such that scores ranged from 5 to 35 . Higher scores indicated a higher level of life satisfaction. The scale shows good convergent validity with other scales and assessments of subjective well-being, as well as discriminant validity with emotional well-being measures (Lucas et al., 1996). Cronbach's alpha for the scale was .87 at Time 1 and .90 at Time 2. 


\section{Control variables.}

Gender, race, and residency were established from dichotomous variables ( $0=$ male, $1=$ female; $0=$ white, $1=$ nonwhite; $0=$ off-campus, $1=$ on campus). Since life satisfaction disparities exist for Blacks and Hispanics (Barger et al., 2009), as well as females (Moksnes \& Espnes, 2013), gender and race were controlled for in all analyses. Moreover, controlling for life satisfaction at Time 1 while predicting life satisfaction at Time 2 allowed us to control for baseline levels of life satisfaction and thereby assess changes in life satisfaction across the transition to college. Previous research demonstrated that attachment disparities existed between first-year college students living away from home (residential students) compared to students living at home (commuter student). Specifically, Larose and Boivin (1998) reported significant increases in security scores for resident students compared to students living at home. As a result, residency was also controlled in all analyses.

\section{Analytic Strategy}

To test our first hypothesis, we conducted a hierarchical linear regression in which we predicted Time 2 life satisfaction from Time 1 positive and negative social exchanges, controlling for gender (female), race (nonwhite), residency (on campus), and Time 1 life satisfaction. In this way, we were able to predict changes in life satisfaction. To test our remaining hypotheses, we conducted a series of hierarchical linear regressions in which we predicted Time 2 life satisfaction from Time 1 positive and negative social exchanges and Time 1 attachment styles, as well as their interactions, controlling for gender (female), race (nonwhite), residency (on campus), and Time 1 life satisfaction. We separately ran a total of four of these regressions for (1) attachment anxiety interacting with positive social exchanges, (2) attachment anxiety interacting with negative social exchanges, (3) attachment avoidance interacting with positive social exchanges, and (4) attachment avoidance interacting with negative social exchanges. In the cases in which the interaction was significant, we ran additional hierarchical linear regressions using the social exchange subscales to explore what specific types of interactions might be driving findings. Since avoidant attachment and anxious attachment were moderately correlated $(r=.31, p=.001)$, we controlled for anxious attachment in all analyses focused on avoidance, and vice versa. The control variables, Time 1 life satisfaction, gender (female), race (nonwhite), and residency (on campus), were entered in the first step. The Time 1 social exchange subscale and Time 1 attachment styles (anxious and avoidant) were added in the second step. In the third step, we added the interaction term between the social exchange (sub)scale and the attachment style of interest (e.g., informational support $\mathrm{x}$ anxious attachment). At each step, we examined $R 2$ change to see if additional variance was accounted for by the predictor variables.

\section{Results}

\section{Descriptive}

Table 1 provides descriptive information and intercorrelations among all study variables $(N=108)$. Most notably, life satisfaction at both time points was positively correlated with positive exchanges and negatively correlated with negative exchanges and both styles of attachment. Attachment anxiety was negatively correlated with positive exchanges and positively correlated with negative exchanges. Attachment avoidance was negatively associated with positive exchanges only. Attachment avoidance and anxiety were positively correlated, and positive and negative exchanges were negatively correlated. Finally, we conducted a repeatedmeasures analysis of covariance (ANCOVA) including the covariates mentioned above, and found no significant change in life satisfaction from Time 1 to Time 2. 
Table 1: Percentages, or Means and Standard Deviations, and Intercorrelations Among All Study Variables ( $\mathrm{N}=108)$.

\begin{tabular}{|c|c|c|c|c|c|c|c|c|c|c|c|}
\hline & $M(\%)$ & $S D$ & 1 & 2 & 3 & 4 & 5 & 6 & 7 & 8 & 9 \\
\hline 1. Female & 85.2 & $\mathrm{n} / \mathrm{a}$ & --- & & & & & & & & \\
\hline 2. Nonwhite & 31.8 & $\mathrm{n} / \mathrm{a}$ & -0.05 & --- & & & & & & & \\
\hline 3. On campus & 63.9 & $\mathrm{n} / \mathrm{a}$ & -0.01 & -0.07 & --- & & & & & & \\
\hline 4. Positive Exchanges & 3.11 & 0.69 & 0.14 & -0.09 & -0.03 & --- & & & & & \\
\hline 5. Negative Exchanges & 1.18 & 0.63 & -0.02 & -0.08 & -0.17 & $-0.34^{* *}$ & --- & & & & \\
\hline 6. Attachment Anxiety & 3.46 & 1.16 & 0.14 & -0.17 & -0.18 & $-0.29^{* *}$ & $0.56^{* *}$ & --- & & & \\
\hline 7. Attachment Avoidance & 3.02 & 0.86 & 0.03 & 0.15 & -0.02 & $-0.29^{* *}$ & 0.18 & $0.31^{* *}$ & --- & & \\
\hline 8. Life Satisfaction, $\mathrm{T} 1$ & 24.65 & 6.04 & -0.02 & -0.10 & 0.12 & $0.42^{* *}$ & $-0.38^{* *}$ & $-0.50^{* *}$ & $-0.49^{* *}$ & -- & \\
\hline 9. Life Satisfaction, T2 & 24.14 & 6.82 & -0.04 & -0.08 & -0.05 & $0.45^{* *}$ & $-0.21^{*}$ & $-0.40^{* *}$ & $-0.43^{* *}$ & $0.68^{* *}$ & --- \\
\hline
\end{tabular}

Note. Ranges: positive and negative social exchanges (0-4); attachment (1-7); life satisfaction $(5-35) .{ }^{\dagger} p<.10,{ }^{*} p<.05$, ${ }^{* *} p<.01,{ }^{* * *} p<.001$. 


\section{Hierarchical Multiple Linear Regressions}

\section{Predicting life satisfaction from social exchanges}

First, we conducted a hierarchical linear regression in which we predicted Time 2 life satisfaction from Time 1 positive and negative social exchanges, controlling for Time 1 life satisfaction, gender (female), race (nonwhite), and residency (on campus) (not shown in a table). Consistent with our first hypothesis regarding the association between social exchanges and life satisfaction, positive social exchanges positively predicted changes in life satisfaction ( $\beta=2.23, p=.007$ ). However, contrary to our hypothesis, negative exchanges at Time 1 did not significantly predict changes in life satisfaction across the first year of college $(\beta=.914, p=$ $.291)$.

\section{Predicting life satisfaction from negative social exchanges and their interaction with attachment anxiety}

Next, we conducted a hierarchical linear regression in which we predicted Time 2 life satisfaction from Time 1 negative exchanges and their interaction with attachment anxiety, while controlling for Time 1 life satisfaction, attachment avoidance, gender, residency, and race. Consistent with our hypothesis, and as shown in Step 3 of the first (left-most) regression in Table 2, we found that attachment anxiety moderated the association between changes in life satisfaction and negative social exchanges $(\beta=0.16, p=.04)$. However, probing showed that the moderation was not in the direction that we predicted. Figure 1 shows differences in $T$-standardized residuals of Time 2 life satisfaction (factoring out gender, race, residency, attachment avoidance, and Time 1 life satisfaction) for individuals high (above the median) and low (below the median) on attachment anxiety, and high and low on negative exchanges. As seen in this figure, for individuals high on attachment anxiety, those reporting high levels of negative social exchanges did not differ in Time 2 life satisfaction from those low on attachment anxiety, whereas those highly anxious individuals reporting low levels of negative social exchanges reported much lower levels of Time 2 life satisfaction than less anxious individuals. 
Table 2: Results of Hierarchical Linear Regression Predicting Life Satisfaction From Negative Social Exchanges and Their Interactions With Attachment Anxiety

\begin{tabular}{|c|c|c|c|c|c|c|c|c|c|}
\hline \multirow[b]{2}{*}{ Predictor Variables } & \multicolumn{3}{|c|}{ Negative Social Exchanges } & \multicolumn{3}{|c|}{ Failure to Provide Help } & \multicolumn{3}{|c|}{ Unwanted Advice } \\
\hline & Step 1 & Step 2 & Step 3 & Step 1 & Step 2 & Step 3 & Step 1 & Step 2 & Step 3 \\
\hline Life Satisfaction & $.64^{* * *}$ & $.62^{* * *}$ & $.66^{* * *}$ & $.63^{* * *}$ & $.59^{* * *}$ & $.61^{* * *}$ & $.64^{* * *}$ & $.60^{* * *}$ & $.65^{* * *}$ \\
\hline Attachment Avoidance & -.11 & -.09 & -.06 & -.11 & -.09 & -.08 & -.10 & -.08 & -.08 \\
\hline Female & -.06 & -.05 & -.05 & -.07 & -.06 & -.08 & -.06 & -.06 & -.03 \\
\hline On campus & $-.13^{\dagger}$ & $-.14^{+}$ & $-.13^{\dagger}$ & $-.13^{+}$ & $-.15^{\dagger}$ & $-.13^{\dagger}$ & -.12 & -.12 & -.11 \\
\hline Nonwhite & -.03 & -.05 & -.06 & -.03 & -.05 & -.07 & -.02 & -.05 & -.06 \\
\hline Negative Social Exchanges & & .10 & .06 & & -.02 & -.08 & & $.18^{*}$ & $.22^{* *}$ \\
\hline Attachment Anxiety & & -.14 & -.12 & & -.08 & -.06 & & -.12 & $-.15^{\dagger}$ \\
\hline \multirow{3}{*}{$\begin{array}{l}\text { Attachment Anxiety x Negative } \\
\text { Social Exchanges }\end{array}$} & & & $.16^{*}$ & & & $.20^{*}$ & & & $.25^{* * *}$ \\
\hline & $R^{2}$ & & .53 & & & .52 & & & .58 \\
\hline & $\Delta R^{2}$ & & .02 & & & .03 & & & .06 \\
\hline
\end{tabular}

Note. Standardized betas presented. ${ }^{\dagger} p<.10,{ }^{*} p<.05,{ }^{* *} p<.01,{ }^{* * * *} p<.001$. 
Parmenter \& Fiori, 2021

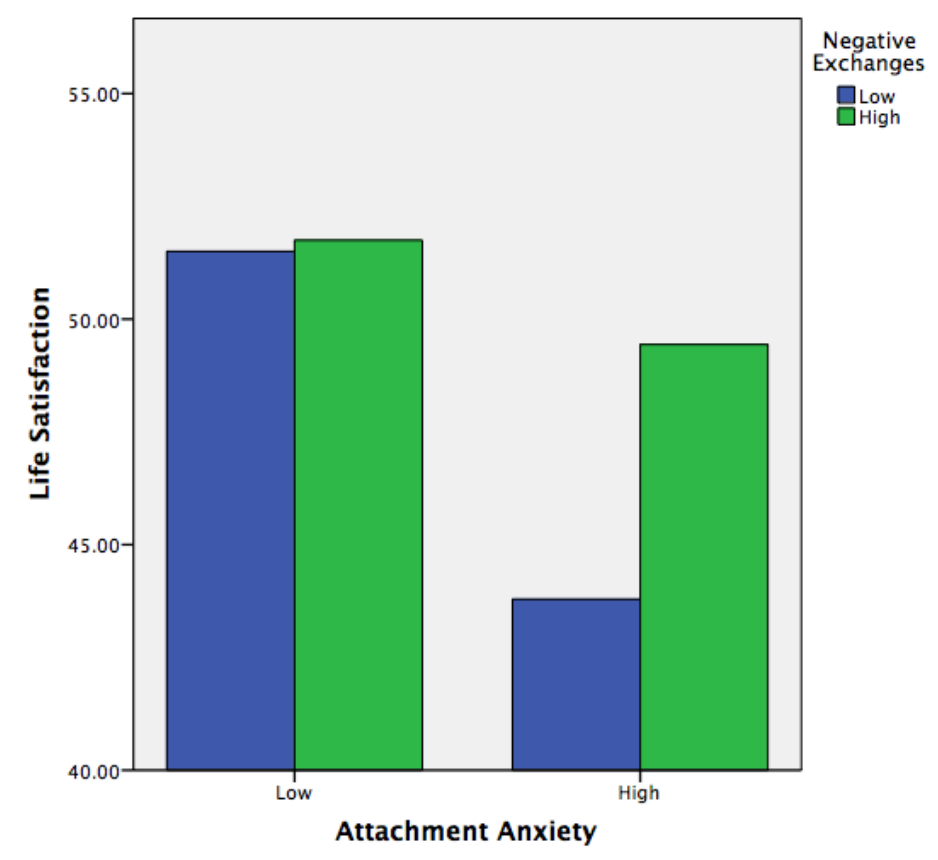

Figure 1: Attachment anxiety as a moderator of the association between negative social exchanges and life satisfaction. The y-axis represents a T-standardized residual of Time 2 life satisfaction factoring out gender, race, residency, attachment avoidance, and Time 1 life satisfaction.

In order to explore which specific types of negative exchanges might be driving this moderation, we conducted similar analyses but using the negative exchange subscales rather than the global scale. We found significant moderation for only two of the subscales: unwanted advice or intrusion $(\beta=.25, p=.001)$ and failure to provide help ( $\beta=.20, p=.013$; shown in Table 2). Specifically, as shown in Figures 2A and 2B, individuals high on attachment anxiety who reported high levels of unwanted advice (2A) or high levels of failure to provide help (2B) did not differ in terms of Time 2 life satisfaction from those low on attachment anxiety. In contrast, those highly anxious individuals who reported low levels of either unwanted advice or failure to provide help showed much lower levels of Time 2 life satisfaction than less anxious individuals. 

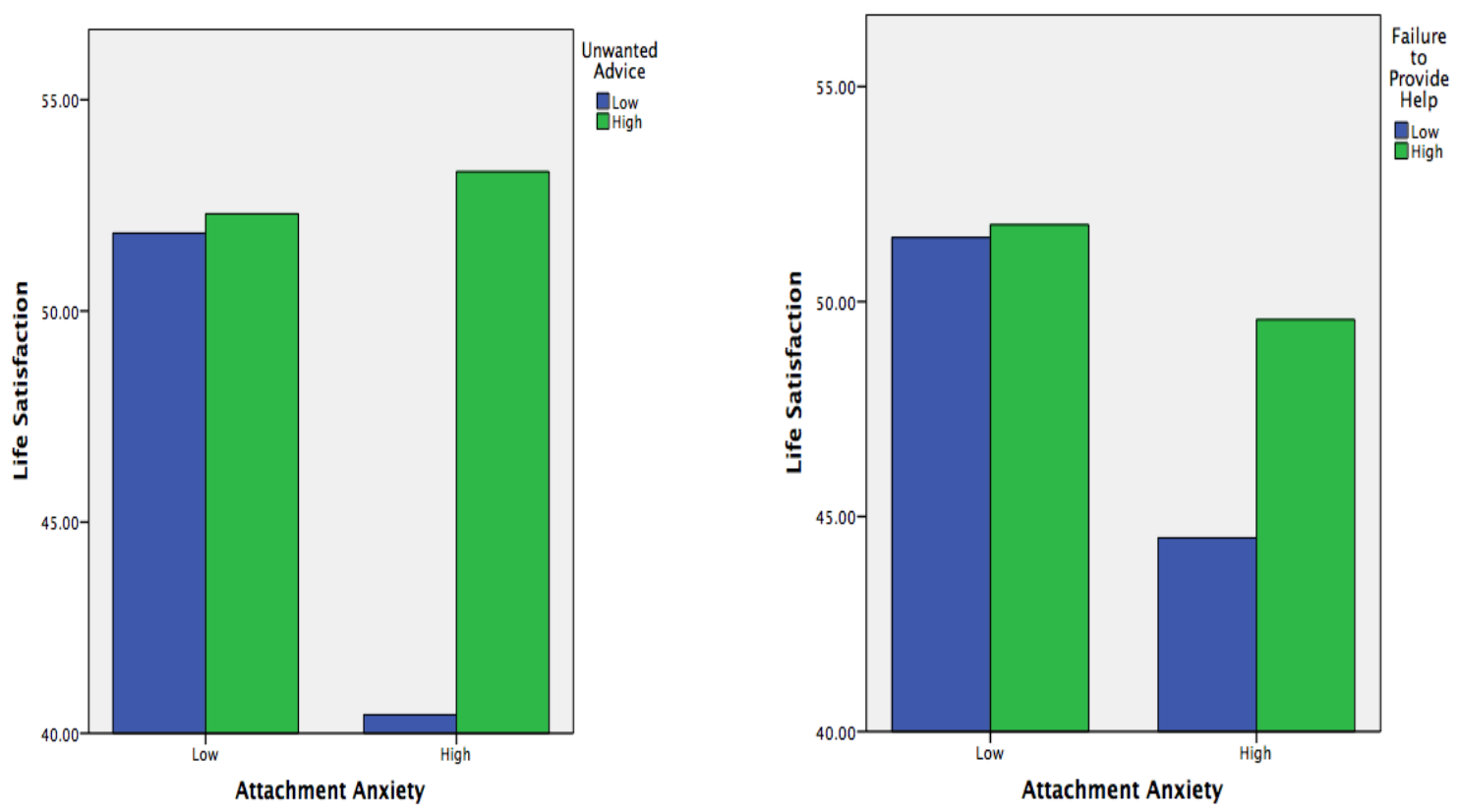

Figure 2A: Attachment anxiety as a moderator of the association between unwanted advice and life satisfaction.

Figure 2B: Attachment anxiety as a moderator of the association between failure to provide help and life satisfaction. The $y$-axis represents a T-standardized residual of Time 2 life satisfaction factoring out gender, race, residency, attachment avoidance, and Time 1 life satisfaction.

\section{Predicting life satisfaction from positive social exchanges and their interaction with attachment anxiety}

Our hypothesis that the positive association between positive social exchanges and life satisfaction would be weaker among individuals with high levels of anxiety attachment was not supported, as the interaction term was not significant $(\beta=-.08, p=.31)$. Furthermore, attachment anxiety did not significantly moderate the association between any of the positive exchange subscales and changes in life satisfaction.

\section{Predicting life satisfaction from negative social exchanges and their interaction with attachment avoidance}

Next, we conducted a hierarchical linear regression in which we predicted Time 2 life satisfaction from Time 1 negative exchanges and their interaction with attachment avoidance, while controlling for Time 1 life satisfaction, attachment anxiety, gender, residency, and race. Consistent with our hypothesis, and as shown in Step 3 of the left-most regression (Table 3), we found that attachment avoidance moderated the association between negative social exchanges and changes in life satisfaction $(\beta=.18, p=.016)$. Specifically, and as shown in Figure 3, we found that among those low in attachment avoidance, negative exchanges do not appear related to life satisfaction, whereas those high in avoidance who reported low levels of negative social exchanges showed much lower levels of Time 2 life satisfaction compared to those who reported high levels of negative social exchanges. 
Table 3: Results of Hierarchical Linear Regression Predicting Life Satisfaction From Negative Social Exchanges and Their Interactions With Attachment Avoidance

\begin{tabular}{|c|c|c|c|c|c|c|c|c|c|c|}
\hline \multirow[b]{2}{*}{ Predictor Variables } & & \multicolumn{3}{|c|}{ Negative Social Exchanges } & \multicolumn{3}{|c|}{ Failure to Provide Help } & \multicolumn{3}{|c|}{ Insensitive Behavior } \\
\hline & & Step 1 & Step 2 & Step 3 & Step 1 & Step 2 & Step 3 & Step 1 & Step 2 & Step 3 \\
\hline Life Satisfaction & & $.64^{* * * *}$ & $.62^{* * * *}$ & $.64^{* * * *}$ & $.63^{* * *}$ & $.59^{* * *}$ & $.59^{* * * *}$ & $.63^{* * *}$ & $\cdot 57^{* * * *}$ & $.58^{* * *}$ \\
\hline Attachment Anxiety & & -.10 & -.14 & -.12 & -.10 & -.08 & -.08 & -.10 & -.05 & -.02 \\
\hline Female & & -.06 & -.05 & -.03 & -.06 & -.06 & -.05 & -.06 & -.06 & -.05 \\
\hline On campus & & $-.15^{*}$ & $-.14^{+}$ & $-.14^{+}$ & $-.15^{*}$ & $-.15^{\dagger}$ & $-.15^{*}$ & $-.16^{*}$ & $-.16^{*}$ & $-.16^{*}$ \\
\hline Nonwhite & & -.07 & -.05 & -.08 & -.07 & -.05 & -.08 & -.08 & -.07 & -.09 \\
\hline Negative Social Exchanges & & & .10 & .11 & & -.02 & -.04 & & -.08 & -.04 \\
\hline Attachment Avoidance & & & -.09 & -.11 & & -.09 & -.09 & & -.11 & -.09 \\
\hline \multirow{3}{*}{$\begin{array}{l}\text { Attachment Avoidance x } \\
\text { Negative Social Exchanges }\end{array}$} & & & & $.18^{*}$ & & & $.15^{*}$ & & & $.17^{*}$ \\
\hline & $R^{2}$ & & & .54 & & & .51 & & & .52 \\
\hline & $\Delta R^{2}$ & & & .03 & & & .02 & & & .03 \\
\hline
\end{tabular}

Note. Standardized betas presented. ${ }^{\dagger} p<.10,{ }^{*} p<.05,{ }^{* *} p<.01,{ }^{* * *} p<.001$. 


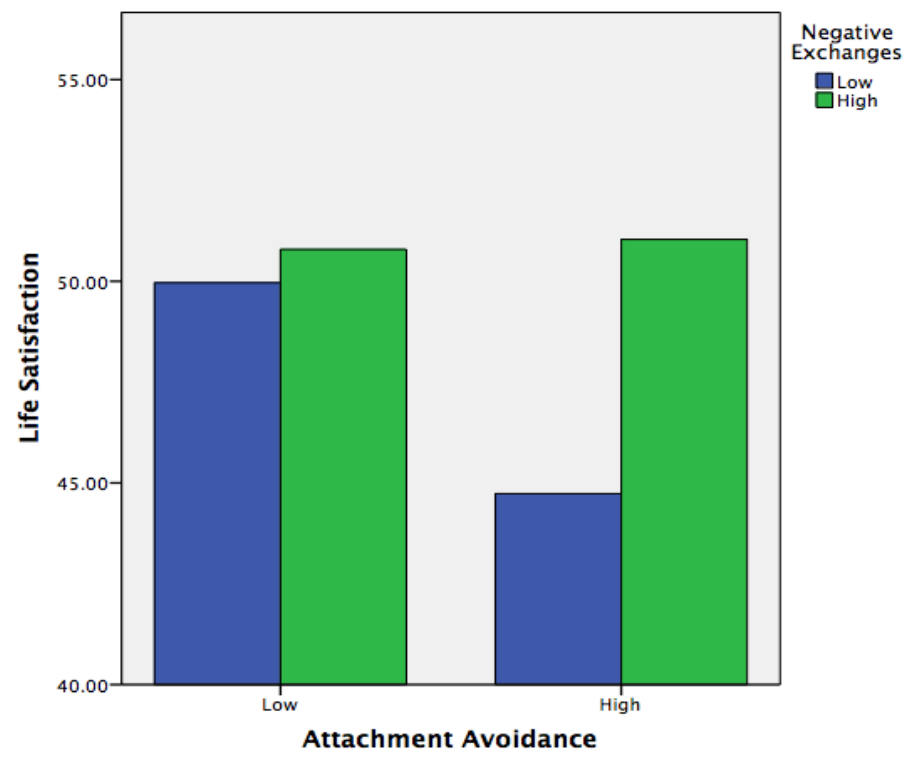

Figure 3: Attachment avoidance as a moderator of the association between negative exchanges and life

satisfaction. The $y$-axis represents a $\mathrm{T}$ standardized residual of Time 2 life satisfaction factoring out gender, race, residency, attachment anxiety, and Time 1 life satisfaction.

Once again, in order to determine what types of specific negative exchanges might be driving this moderation, we conducted parallel analyses using the negative social exchange subscales. We found moderation in the case of only two subscales: failure to provide help $(\beta=0.15, p=.046)$ and insensitive behavior $(\beta=0.17, p=.03)$. In both cases, and as shown in Figure $4 \mathrm{~A}$ and $4 \mathrm{~B}$, for individuals high on avoidance, those reporting higher levels of these subscales of negative exchanges had greater increases in life satisfaction than those reporting lower levels. In contrast, these subscales were not associated with changes in life satisfaction for individuals low on attachment avoidance.
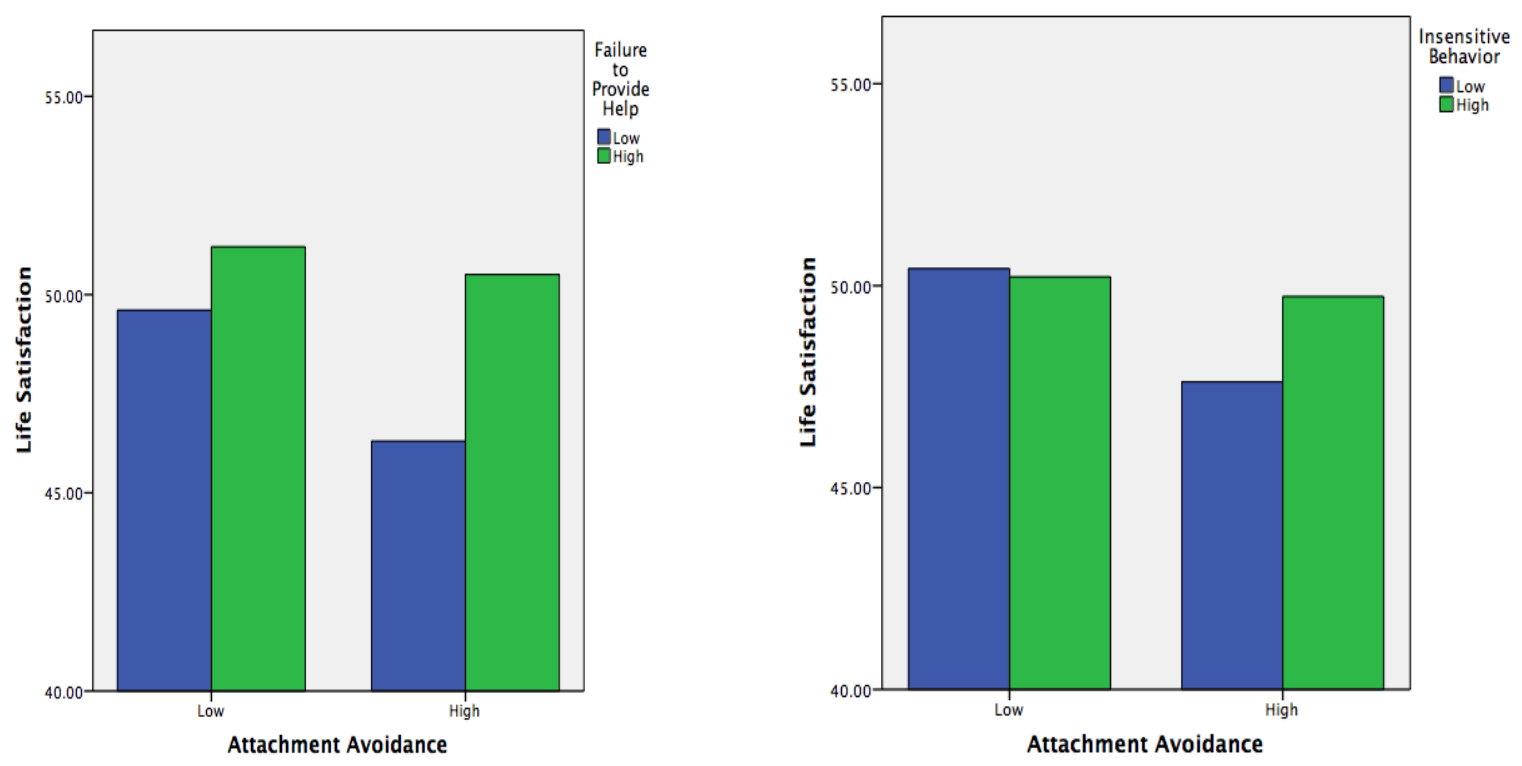

Figure 4A: Attachment avoidance as a moderator of the association between failure to provide help and life satisfaction.

Figure 4B: Attachment avoidance as a moderator of the association between insensitive behavior and life satisfaction. The $y$-axis represents a T-standardized residual of Time 2 life satisfaction factoring out gender, race, residency, attachment anxiety, and Time 1 life satisfaction. 
Table 4: Results of Hierarchical Linear Regression Predicting Life Satisfaction From Positive Social Exchanges and Their Interactions With Attachment Avoidance

\begin{tabular}{|c|c|c|c|c|c|c|c|c|c|c|}
\hline \multirow[b]{2}{*}{ Predictor Variables } & & \multicolumn{3}{|c|}{ Positive Social Exchanges } & \multicolumn{3}{|c|}{ Informational Support } & \multicolumn{2}{|c|}{ Companionship } & \multirow[b]{2}{*}{ Step 3} \\
\hline & & Step 1 & Step 2 & Step 3 & Step 1 & Step 2 & Step 3 & Step 1 & Step 2 & \\
\hline Life Satisfaction & & $.64^{* * *}$ & $.55^{* * *}$ & $.57^{* * *}$ & $.65^{* * *}$ & $.55^{* * *}$ & $.59^{* * *}$ & $.64^{* * *}$ & $.59^{* * *}$ & $.62^{* * *}$ \\
\hline Attachment Anxiety & & -.10 & -.06 & -.07 & -.10 & -.08 & -.07 & -.10 & -.04 & -.05 \\
\hline Female & & -.06 & -.09 & -.08 & -.05 & -.07 & -.09 & -.06 & -.07 & -.05 \\
\hline On campus & & $-.15^{*}$ & $-.12^{\dagger}$ & $-.14^{\dagger}$ & $-.15^{*}$ & -.11 & $-.13^{\dagger}$ & $-.15^{*}$ & $-.14^{\dagger}$ & $-.14^{*}$ \\
\hline Nonwhite & & -.07 & -.05 & -.06 & -.06 & -.03 & -.03 & -.07 & -.04 & -.07 \\
\hline Social Exchanges & & & $.19^{*}$ & $.19^{*}$ & & $.19^{*}$ & $.18^{*}$ & & $.14^{\dagger}$ & .11 \\
\hline Attachment Avoidance & & & -.08 & -.02 & & -.08 & -.07 & & -.09 & -.04 \\
\hline \multirow[t]{3}{*}{ Interaction } & & & & $-.17^{*}$ & & & $-.15^{*}$ & & & $-.19^{*}$ \\
\hline & $R^{2}$ & & & .55 & & & 0.56 & & & .55 \\
\hline & $\Delta R^{2}$ & & & .03 & & & .02 & & & .03 \\
\hline
\end{tabular}

Note. Standardized betas presented. ${ }^{\dagger} p<.10,{ }^{*} p<.05,{ }^{* *} p<.01,{ }^{* * *} p<.001$. 


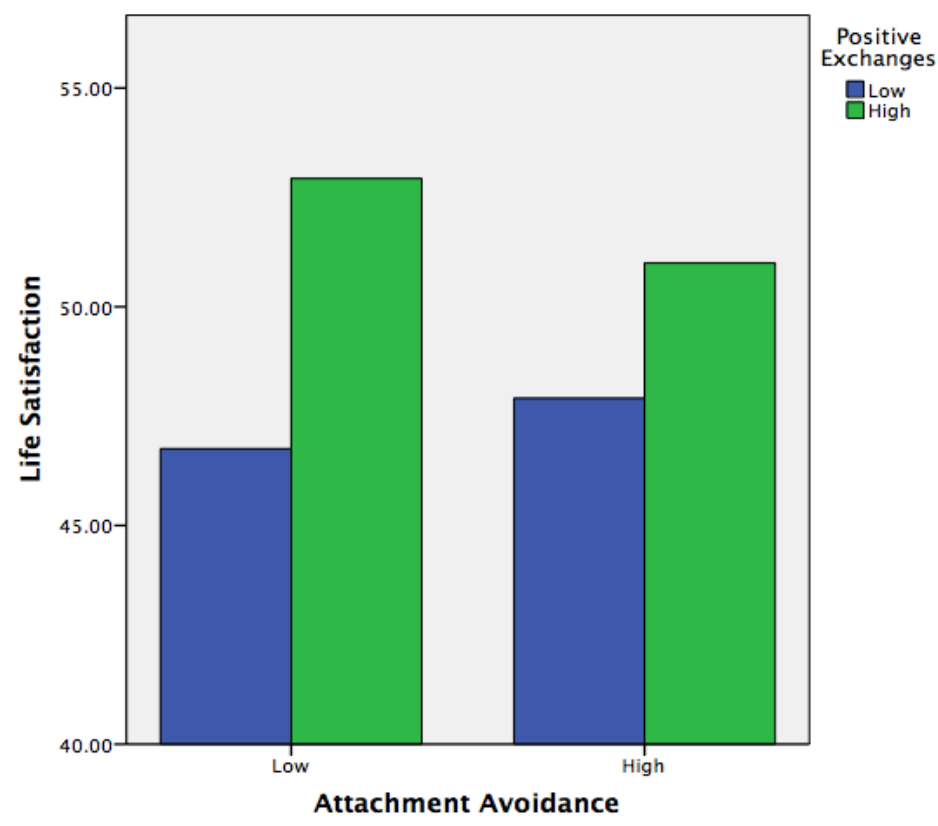

Figure 5: Attachment avoidance as a moderator of the association between positive social exchanges and life satisfaction. The $y$-axis represents a $\mathrm{T}$-standardized residual of Time 2 life satisfaction factoring out gender, race, residency, attachment anxiety, and Time 1 life satisfaction.

\section{Predicting life satisfaction from positive social exchanges and their interaction with attachment avoidance}

Lastly, we conducted a hierarchical linear regression in which we predicted Time 2 life satisfaction from Time 1 positive exchanges and their interaction with attachment avoidance. The same control variables were included in Step 2. Consistent with our hypothesis, and as shown in Step 3 of the left-most regression in Table 4, we found that attachment avoidance moderated the association between life satisfaction and positive social exchanges $(\beta=-.17, p=.023)$. Specifically, and as shown in Figure 5 , for individuals low on avoidance, positive social exchanges appear to be more strongly positively associated with changes in life satisfaction than for individuals high on avoidance.

Finally, in order to determine what specific types of positive exchanges might be driving the moderation, we repeated the analyses using the positive social exchanges subscales and found significant moderation for two of the subscales: informational support $(\beta=-.15, p=.029)$ and companionship $(\beta=-.19, p=.010)$. Specifically, and as seen in Figure 6A, for individuals low on attachment avoidance, greater reported levels of informational support were associated with much higher reported life satisfaction than lower levels of informational support; in contrast, for those high on avoidance, there was no difference in levels of life satisfaction for those low and high on informational support. Similarly, and as seen in Figure 6B, for individuals low on attachment avoidance, greater reported levels of companionship were associated with much higher reported life satisfaction than lower levels of companionship. However, those highly avoidant individuals who reported high levels of companionship actually showed lower levels of Time 2 life satisfaction. 

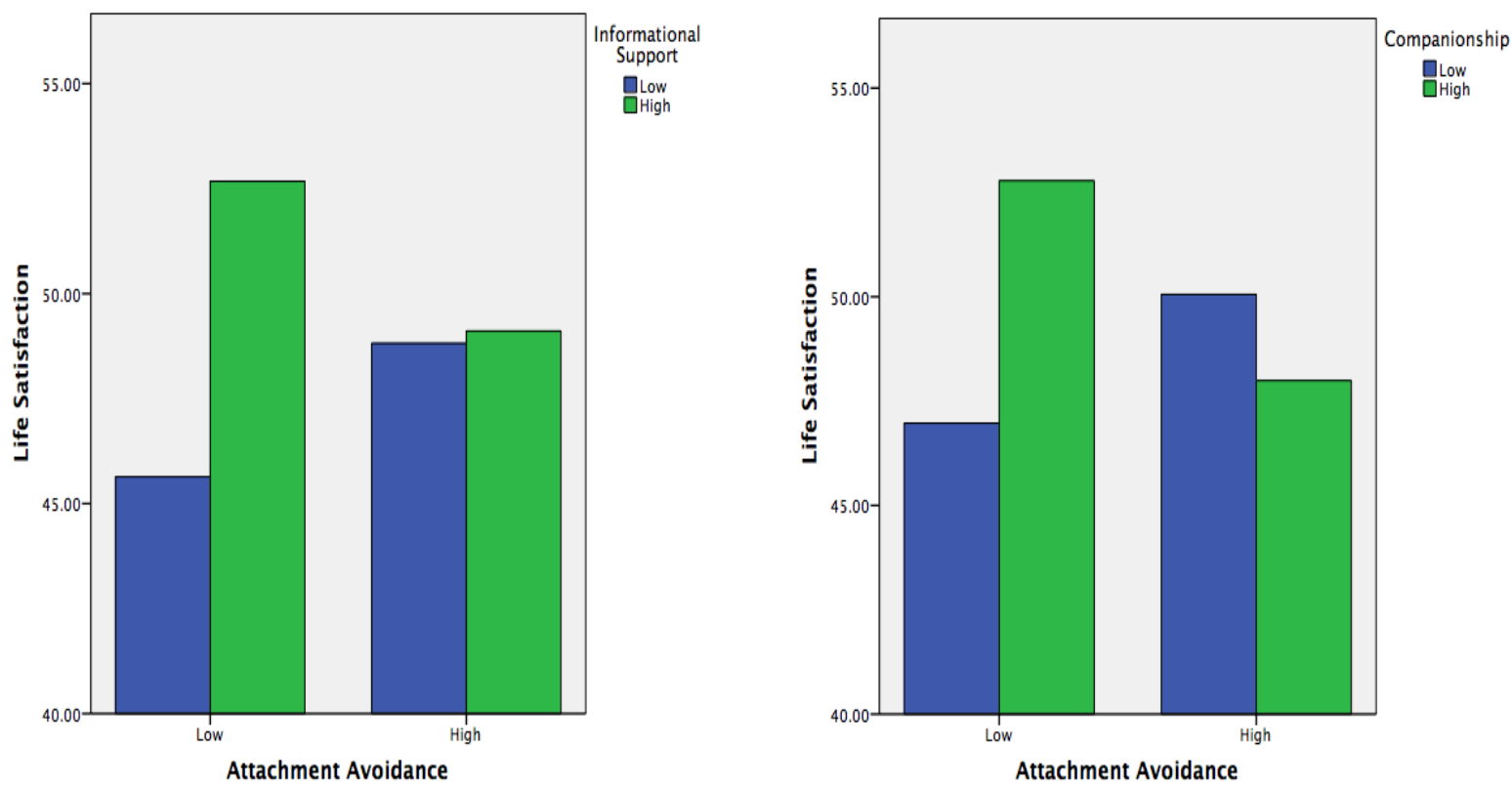

Figure 6A: Attachment avoidance as a moderator of the association between informational support and life satisfaction.

Figure 6B: Attachment avoidance as a moderator of the association between companionship and life satisfaction. The $y$-axis represents a T-standardized residual of Time 2 life satisfaction factoring out gender, race, residency, attachment anxiety, and Time 1 life satisfaction.

\section{Discussion}

The present study highlights the important role of adult attachment styles in understanding how social interactions are associated with changes in well-being, particularly during a time in which young adults are separating themselves from parental attachment figures (Dykas \& Siskind, 2020). Separation-individuation is a key developmental task that occurs for individuals who go away to college, as well as those who stay at home (Mattanah, 2004). However, studies provide some empirical support for the idea that individual differences related to attachment are magnified, and more easily observed, during times of stress (Adam et al., 2004). Since the transition to college may be especially stressful for those students who leave home, their attachment system is more likely to be activated (Bernier et al., 2005).

After controlling for residency, gender, race, and Time 1 life satisfaction, we found that attachment insecurity moderated the association between social exchanges and changes in life satisfaction across the first year of college. Specifically, for those high on either attachment anxiety or attachment avoidance, those reporting low levels of negative exchanges reported much lower levels of life satisfaction at Time 2 (controlling for Time 1 life satisfaction) than less anxious or less avoidant individuals. In addition, whereas positive exchanges were associated with increases in life satisfaction among participants low on attachment avoidance, they were associated with decreases in life satisfaction among participants high on avoidance. We outline our findings in more detail below, highlighting how they contribute to the large body of research on social support, social strain, and well-being (Chen \& Feeley, 2014; Okun \& Keith, 1998; Rook, 1990; Schuster et al., 1990; Uchino, 2009; Walen \& Lachman, 2000).

\section{Social Exchange and Life Satisfaction: The Role of Attachment Insecurity}

Our first hypothesis that positive social exchanges would be positively associated and negative social exchanges negatively associated with changes in life satisfaction was partially supported. Whereas positive exchanges were significantly associated with increases in life satisfaction, negative exchanges were not related 
to changes in life satisfaction. Relational regulation theory (Lakey \& Orehek, 2011) provides a broad perspective for understanding these findings and suggests that the types of interactions that regulate recipients may be attributable to attachment dimensions. Though at first surprising, it is likely that the null effects for negative exchanges stem from the presence of moderation by attachment insecurity. For example, partially consistent with our first hypothesis, we found that attachment anxiety moderated the association between negative (but not positive) social exchanges and changes in life satisfaction.

Because of a large body of research supporting the "negativity effect" model (Newsom et al., 2003; Rook, 1990, 2001), in which negative social exchanges exhibit stronger and more reliable associations with wellbeing than do positive exchanges (Ingersoll-Dayton et al., 1997), we hypothesized that negative social exchanges would actually be more strongly associated with decreases in life satisfaction for highly anxious individuals. Interestingly, however, our finding was in the opposite direction. That is, for participants who were high on attachment anxiety (i.e., more insecure), negative exchanges were associated with increases in life satisfaction. These findings may be understood in light of research showing that preoccupied (anxiousambivalent) individuals demonstrate more positive emotion and satisfaction following high-conflict interactions (Pietromonaco \& Barrett, 1997). It may be that negative exchanges provide an opportunity for anxiously attached individuals to establish greater intimacy and obtain some degree of responsiveness from their exchange partner.

Moreover, college students with preoccupied attachment styles report having more negative relationships with their parents than their secure peers, yet they also have more contact with them (Bernier et al., 2005). In the present study, post-hoc analyses revealed that individuals high on attachment anxiety reported a significantly higher mean number of negative social exchanges than individuals low on attachment anxiety. This supports the idea that anxiously attached individuals may provoke more negative exchanges, as evidenced by their tendency to engage with people whom they report conflictual relationships and/or perceive exchanges to be more negative than their securely attached peers.

Overall, these effects were driven by the "unwanted advice and intrusion" and "failure to provide help" subscales of the PANSE (Newsom et al., 2005). Whereas secure individuals and/or those high on avoidance may reject unwanted advice from others, anxious individuals have a much higher demand for help. For example, they frequently doubt their own capabilities and depend more heavily on others as sources of information (Collins \& Read, 1990). Therefore, when others meddle in their personal matters and question their decisions, anxiously attached individuals may view this as support rather than intrusion. Furthermore, although anxiously attached individuals rely more heavily on others, their perceptions of others vary (i.e., they are not uniformly positive but are instead dependent on the context). For instance, Pietromonaco and Barrett (1997) found that preoccupied individuals held more positive views of others following high-conflict versus low-conflict interactions. Thus, it is possible that situations in which participants perceived others as letting them down and/or failing to provide them with the assistance they were counting on resulted in conflict. However, the resolution of this conflict may have provided an opportunity to get their attachment needs met (i.e., to seek and receive help).

Avoidant attachment also moderated the association between negative social exchanges and changes in life satisfaction. Similarly, compared to those high in attachment anxiety, we found that among those high in attachment avoidance negative exchanges were associated with increases in life satisfaction. In line with attachment theory (Collins \& Read, 1990), this suggests that avoidant individuals may be relieved when they experience interactions that confirm their negative expectations. Consistent with this reasoning, this moderation effect seemed to be driven primarily by the "unsympathetic or insensitive behavior" and "failure to provide help" subscales. Because avoidant individuals hold consistently positive views of themselves and negative views of others (Carnelley et al., 1994), when interaction partners are thoughtless and inconsiderate it may correspond with their working models of others as unsupportive (Kobak \& Scerry, 1988). Furthermore, 
Parmenter \& Fiori, 2021

since avoidant individuals prefer independence (Bartholomew \& Horowitz, 1991), they may be more satisfied when others are unavailable and/or fail to provide assistance. In sum, whereas network partners failing to provide help may be associated with hyperactivating attachment strategies for anxious individuals, they are more likely associated with deactivating strategies among avoidant individuals.

Although we found more consistent associations with life satisfaction for negative exchanges compared to positive exchanges, in line with the negativity effect, these associations were in the opposite direction, at least among those high on either attachment anxiety or attachment avoidance. Our findings imply that the negativity effect may not operate similarly for all groups of individuals. Furthermore, the negativity effect has been found mostly for older adults (Finch et al., 1989) who tend to experience fewer negative exchanges than young adults. Since young adults experience more frequent negative exchanges (Okun \& Keith, 1998), more research is needed to explore whether the negativity effect is equally pertinent for younger adults who are embedded in very different social contexts compared to older adults.

Consistent with our third hypothesis, we found that the association between positive social exchanges and life satisfaction was also moderated by attachment avoidance. Specifically, for participants high on attachment avoidance, positive social exchanges were not as strongly positively associated with changes in life satisfaction. It may be that individuals who are highly avoidant thrive on negative social exchanges, without experiencing the benefits of positive social exchanges. Interestingly, these results were driven primarily by the "information support" and "companionship" subscales. Evidence of the importance of companionship, in particular, converges with other studies that have identified the unique contributions of companionship to health and well-being (e.g., Bolger \& Eckenrode, 1991; Newsom et al., 2005; Rook, 1987). It may be that whereas individuals low in attachment avoidance thrive in social contexts, such as when others include them in recreational activities or provide them with company, individuals high on attachment avoidance may prefer more solitary activities.

\section{Considerations and Conclusions}

This study had several strengths, including a longitudinal design and a consideration of individual differences in the associations between social exchanges and life satisfaction. Of course, there are several limitations that should be considered. First, the study relied on retrospective reports of social exchanges, with participants asked to report the frequency of exchanges over a one-month period. This may have produced a recall bias, as some exchanges that occur infrequently may still have powerful effects. However, this time frame is likely appropriate for capturing a reasonable estimate of social exchanges given its common use in mental health studies (Newsom et al., 2005). Further, whereas microanalytic methods (e.g., event-contingent diaries) allow researchers to capture information about interactions immediately after they occur (Reis \& Wheeler, 1991), retrospective reports provide more memory-based, global theories of participants' perceptions of themselves and others.

Second, we did not examine the source of exchanges. Although past research has demonstrated differences in whom college students turn for certain types of support, the combination of support from friends, family, and romantic partners appears to be most profitable for students' subjective well-being (Ratelle et al., 2013). Furthermore, given their preference for maintaining distance, avoidantly attached individuals in particular are less likely to differentiate between non-close and close others (Pietromonaco \& Barrett, 1997).

Third, females $(n=92)$ and white students $(n=72)$ outnumbered males and non-white students in the sample, which may limit the generalizability of our findings. Differences in living status (resident vs. commuter) were also found, but in the direction that reflects national averages (Simpson \& Burnett, 2019). Although commuter students continue to be viewed as "nontraditional," they comprise more than $85 \%$ of today's college students (Jacoby, 2020). With this in mind, future research may want to ask more detailed questions about the living arrangements of commuter students, specifically if these students are (1) living in 
the home of a parent, guardian or relative, or (2) living on their own or with others, as differences in dependency and self-reliance exist within these two groups (Dugan et al., 2008). Finally, the correlational design of the study does not allow us to infer causality; it is likely that the association between social exchanges and life satisfaction is bidirectional, such that, for example, increases in life satisfaction may evoke greater positive exchanges.

Future studies could employ an experimental design to determine if participants high in avoidant attachment perceive social exchanges to be more negative, evoke more negative responses from others, or find negative exchanges to be reinforcing. Future research may also consider examining different categories of adult attachment (i.e., secure, preoccupied, dismissing, and fearful-avoidant), rather than the dimensions of anxiety and avoidance; for example, individuals with dismissing-avoidant and fearful-avoidant tendencies may show different patterns. Finally, it will be important in future research to determine whether the same patterns seen here in a college student sample would also arise in a sample of older adults for whom attachment issues may resurface as functional declines necessitate greater dependency on others and for whom negative social exchanges may be more detrimental (Newsom et al., 2005). In sum, our findings show that negative social exchanges may actually benefit individuals who are highly anxious or avoidant, implying that there may be a positive side to negative interactions. 


\section{References}

Adam, E. K., Gunnar, M. R., \& Tanaka, A. (2004). Adult attachment, parent emotion, and observed parenting behavior: Mediator and moderator models. Child Development, 75, 110-122.

Anders, S. L., \& Tucker, J. S. (2000). Adult attachment style, interpersonal communication competence, and social support. Personal Relationships, 7(4), 379-389. https://doi.org/10.1111/j.14756811.2000.tbooo23.x

Antonucci, T. C. (1985). Social support: Theoretical advances, recent findings and pressing issues. In Social support: Theory, research and applications (pp. 21-37). Springer, Dordrecht.

Barger, S. D., Donoho, C. J., \& Wayment, H. A. (2009). The relative contributions of race/ethnicity, socioeconomic status, health, and social relationships to life satisfaction in the United States. Quality of Life Research, 18(2), 179-189. https://doi.org/10.1007/s11136-008-9426-2

Bartholomew, K. (1990). Avoidance of intimacy: An attachment perspective. Journal of Social and Personal Relationships, 7(2), 147-178.

Bartholomew, K., \& Horowitz, L. M. (1991). Attachment styles among young adults: A test of a four-category model. Journal of Personality and Social Psychology, 61, 226-244.

Berkman, L. F., Glass, T., Brissette, I., \& Seeman, T. E. (2000). From social integration to health: Durkheim in the new millennium. Social Science \& Medicine, 51(6), 843-857. https://doi.org/10.1016/So2779536(00)00065-4

Bernier, A., Larose, S., \& Whipple, N. (2005). Leaving home for college: A potentially stressful event for adolescents with preoccupied attachment patterns. Attachment \& Human Development, 7(2), 171185. https://doi.org/10.1080/14616730500147565

Bertera, E. M. (2005). Mental health in US adults: The role of positive social support and social negativity in personal relationships. Journal of Social and Personal Relationships, 22(1), 33-48. https://doi.org/10.1177/0265407505049320

Birditt, K. S., Antonucci, T. C., \& Tighe, L. (2012). Enacted support during stressful life events in middle and older adulthood: An examination of the interpersonal context. Psychology and Aging, 27(3), 728741. https://doi.org/10.1037/a0026967

Blain, M. D., Thompson, J. M., \& Whiffen, V. E. (1993). Attachment and perceived social support in late adolescence: The interaction between working models of self and others. Journal of Adolescent Research, 8(2), 226-241.

Bolger, N., \& Eckenrode, J. (1991). Social relationships, personality, and anxiety during a major stressful event. Journal of Personality and Social Psychology, 61, 440-449.

Bowlby, J. (1973). Attachment and loss: Vol. 2. Separation, anxiety and anger. The Hogarth Press and the Institute of Psycho-Analysis.

Bowlby, J. (1980). Attachment and loss: Vol. 3. Loss. The Hogarth Press and the Institute of Psycho-Analysis.

Carnelley, K. B., Pietromonaco, P. R., \& Jaffe, K. (1994). Depression, working models of others, and relationship functioning. Journal of Personality and Social Psychology, 66, 127-140.

Chemers, M. M., Hu, L. T., \& Garcia, B. F. (2001). Academic self-efficacy and first-year college student performance and adjustment. Journal of Educational Psychology, 93(1), 55-64. https://doi.org/10.1037/0022-0663.93.1.55

Chen, Y., \& Feeley, T. H. (2014). Social support, social strain, loneliness, and well-being among older adults: An analysis of the Health and Retirement Study. Journal of Social and Personal Relationships, 31(2), 141-161. https://doi.org/10.1177/0265407513488728 
Parmenter \& Fiori, 2021

Cheng, S. T., Li, K. K., Leung, E. M., \& Chan, A. C. (2011). Social exchanges and subjective well-being: Do sources of positive and negative exchanges matter? Journals of Gerontology Series B: Psychological Sciences and Social Sciences, 66(6), 708-718. https://doi.org/10.1093/geronb/gbro61

Chu, P. S., Saucier, D. A., \& Hafner, E. (2010). Meta-analysis of the relationships between social support and well-being in children and adolescents. Journal of Social and Clinical Psychology, 29(6), 624-645. https://doi.org/10.1521/jscp.2010.29.6.624

Coble, H. M., Gantt, D. L., \& Mallinckrodt, B. (1996). Attachment, social competency, and the capacity to use social support. In Handbook of social support and the family (pp. 141-172). Springer.

Cohen S. (2004). Social relationships and health. The American Psychologist, 59(8), 676-684.

Cohen, S., \& Wills, T. A. (1985). Stress, social support, and the buffering hypothesis. Psychological Bulletin, $98,310-357$.

Collins, N. L., \& Feeney, B. C. (2000). A safe haven: An attachment theory perspective on support-seeking and caregiving processes in intimate relationships. Journal of Personality and Social Psychology, 78, 1053-1073. https://doi.org/10.1037/0022-3514.78.6.1053

Collins, N. L., \& Feeney, B. C. (2004). Working models of attachment shape perceptions of social support: Evidence from experimental and observational studies. Journal of Personality and Social Psychology, 87(3), 363-383. https://doi.org/10.1037/0022-3514.87.3.363

Collins, N. L., \& Read, S. J. (1990). Adult attachment, working models, and relationship quality in dating couples. Journal of Personality and Social Psychology, 58(4), 644-663.

Compas, B. E., Wagner, B. M., Slavin, L. A., \& Vannatta, K. (1986). A prospective study of life events, social support, and psychological symptomatology during the transition from high school to college. American Journal of Community Psychology, 14(3), 241-257. https://doi.org/10.1007/BFoog11173

Cotton, S. J., Dollard, M. F., \& De Jonge, J. (2002). Stress and student job design: Satisfaction, well-being, and performance in university students. International Journal of Stress Management, 9(3), 147-162.

Davis, M. H., Morris, M. M., \& Kraus, L. A. (1998). Relationship-specific and global perceptions of social support: Associations with well-being and attachment. Journal of Personality and Social Psychology, 74(2), 468-481.

Diener, E. D., Emmons, R. A., Larsen, R. J., \& Griffin, S. (1985). The satisfaction with life scale. Journal of Personality Assessment, 49(1), 71-75.

Dugan, J. P., Garland, J. L., Jacoby, B., \& Gasiorski, A. (2008). Understanding commuter student self-efficacy for leadership: A within-group analysis. Journal of Student Affairs Research and Practice, 45(2), 454-482.

Dykas, M. J., \& Siskind, D. G. (2020). Turning from parents: Psychological distancing and attachment-related changes in regret for immediate contact in emerging adulthood. Emerging Adulthood, 8(3), 195-208. https://doi.org/10.1177/2167696818799833

Dyson, R., \& Renk, K. (2006). Freshmen adaptation to university life: Depressive symptoms, stress, and coping. Journal of Clinical Psychology, 62(10), 1231-1244. https://doi.org/10.1002/jclp.20295

Fiori, K. L., \& Consedine, N. S. (2013). Positive and negative social exchanges and mental health across the transition to college: Loneliness as a mediator. Journal of Social and Personal Relationships, 30(7), 920-941. https://doi.org/10.1177/0265407512473863 
Parmenter \& Fiori, 2021

Fiori, K. L., Windsor, T. D., Pearson, E. L., \& Crisp, D. A. (2012). Can positive social exchanges buffer the detrimental effects of negative social exchanges? Age and gender differences. Gerontology, 59(1), 4052. https://doi.org/10.1159/000339747

Finch, J. F., Okun, M. A., Barrera, M., Zautra, A. J., \& Reich, J. W. (1989). Positive and negative social ties among older adults: Measurement models and the prediction of psychological distress and well-being American Journal of Community Psychology, 17(5), 585-605.

Finch, J. F., Okun, M. A., Pool, G. J., \& Ruehlman, L. S. (1999). A comparison of the influence of conflictual and supportive social interactions on psychological distress. Journal of Personality, 67(4), 581-621. https://doi.org/10.1111/1467-6494.00066

Florian, V., Mikulincer, M., \& Bucholtz, I. (1995). Effects of adult attachment style on the perception and search for social support. The Journal of Psychology, 129(6), 665-676.

Fraley, R. C. (2012). Information on the experiences in Close Relationships-Revised (ECR-R) Adult Attachment Questionnaire. http://labs.psychology.illinois.edu/ rcfraley/measures/ecrr.htm

Fraley, R. C., Heffernan, M. E., Vicary, A. M., \& Brumbaugh, C. C. (2011). The experiences in close relationships-Relationship Structures Questionnaire: A method for assessing attachment orientations across relationships. Psychological Assessment, 23(3), 615.

https://doi.org/10.1037/a0022898

Fraley, R., Hudson, N., Heffernan, M., \& Segal, N. (2015). Are adult attachment styles categorical or dimensional? A taxometric analysis of general and relationship-specific attachment orientations. Journal of Personality and Social Psychology, 109(2), 354-368. https://doi.org/10.1037/psppoo00027

Fraley, R. C., Waller, N. G., \& Brennan, K. A. (2000). An item response theory analysis of self-report measures of adult attachment. Journal of Personality and Social Psychology, 78(2), 350-365. https://doi.org/10.1037/0022-3514.78.2.350

Friedlander, L. J., Reid, G. J., Shupak, N., \& Cribbie, R. (2007). Social support, self-esteem, and stress as predictors of adjustment to university among first-year undergraduates. Journal of College Student Development, 48(3), 259-274. https://doi.org/10.1353/csd.2007.0024

Gable, S. L., \& Reis, H. T. (2010). Good news! Capitalizing on positive events in an interpersonal context. In Advances in Experimental Social Psychology (pp. 195-257). Academic Press.

Guarnieri, S., Smorti, M., \& Tani, F. (2015). Attachment relationships and life satisfaction during emerging adulthood. Social Indicators Research, 121(3), 833-847. http://doi.org/10.1007/s11205-014-0655-1

Haber, M. G., Cohen, J. L., Lucas, T., \& Baltes, B. B. (2007). The relationship between self-reported received and perceived social support: A meta-analytic review. American Journal of Community Psychology, 39(1-2), 133-144. https://doi.org/10.1007/s10464-007-9100-9

Hannum, J. W., \& Dvorak, D. M. (2004). Effects of family conflict, divorce, and attachment patterns on the psychological distress and social adjustment of college freshmen. Journal of College Student Development, 45(1), 27-42. https://doi.org/10.1353/csd.2004.0008

Herzberg, D. S., Hammen, C., Burge, D., Daley, S. E., Davila, J., \& Lindberg, N. (1999). Attachment cognitions predict perceived and enacted social support during late adolescence. Journal of Adolescent Research, 14, 387-404. https://doi.org/10.1177/0743558499144001

Holmbeck, G. N., \& Wandrei, M. L. (1993). Individual and relational predictors of adjustment in first-year college students. Journal of Counseling Psychology, 4O(1), 73-78. https://doi.org/10.1037/0022$\underline{0167.40 .1 .73}$ 
Holt-Lunstad, J., Smith, T. B., \& Layton, J. B. (2010). Social relationships and mortality risk: A meta-analytic review. PLoS Medicine, 7(7), 1-20. https://doi.org/10.1371/journal.pmed.1000316

House, J. S., Landis, K. R., \& Umberson, D. (1988). Social relationships and health. Science, 241(4865), 540545 .

Howland, M., \& Simpson, J. A. (2010). Getting in under the radar: A dyadic view of invisible support. Psychological Science, 21(12), 1878-1885. https://doi.org/10.1177/0956797610388817

Ingersoll-Dayton, B., Morgan, D., \& Antonucci, T. (1997). The effects of positive and negative social exchanges on aging adults. The Journals of Gerontology, Series B: Psychological Sciences and Social Sciences, 52, S190-S199.

Jacoby, B. (2020, July 23). What about the other 85 percent? Inside Higher Ed. https://www.insidehighered.com/views/2020/07/23/colleges-should-be-planning-moreintentionally-students-who-commute-campuses-fall

Kafetsios, K., \& Nezlek, J. B. (2002). Attachment styles in everyday social interaction. European Journal of Social Psychology, 32(5), 719-735. https://doi.org/10.1002/ejsp.130

Kafetsios, K., \& Sideridis, G. D. (2006). Attachment, social support and well-being in young and older adults. Journal of Health Psychology, 11(6), 863-875. https://doi.org/10.1177/1359105306069084

Kaur, H. (2020, April 17). Forget 'social distancing.' The WHO prefers we call it 'physical distancing' because social connections are more important than ever. CNN. https://www.cnn.com/2020/04/15/world/social-distancing-language-change-trnd/index.html

Kenny, M. E., \& Rice, K. G. (1995). Attachment to parents and adjustment in late adolescent college students: Current status, applications, and future considerations. The Counseling Psychologist, 23(3), 433456.

Kobak, R. R., \& Sceery, A. (1988). Attachment in late adolescence: Working models, affect regulation, and representations of self and others. Child Development, 135-146.

Lakey, B., \& Cronin, A. (2008). Low social support and major depression: Research, theory and methodological issues. In Risk Factors in Depression (pp. 385-408). Elsevier.

Lakey, B., \& Orehek, E. (2011). Relational regulation theory: A new approach to explain the link between perceived social support and mental health. Psychological Review, 118(3), 482-495. https://doi.org/10.1037/a0023477

Lakey, B., Orehek, E., Hain, K. L., \& VanVleet, M. (2010). Enacted support's links to negative affect and perceived support are more consistent with theory when social influences are isolated from trait influences. Personality and Social Psychology Bulletin, 36(1), 132-142. https://doi.org/10.1177/0146167209349375

LaRocco, J. M., House, J. S., \& French, J. R., Jr. (1980). Social support, occupational stress, and health. Journal of Health and Social Behavior, 202-218.

Larose, S., \& Boivin, M. (1998). Attachment to parents, social support expectations, and socioemotional adjustment during the high school-college transition. Journal of Research on Adolescence, 8(1), 1-27.

Lawton, M. P., Moss, M., \& Grimes, M. (1985). The changing service needs of older tenants in planned housing. The Gerontologist, 25(3), 258-264.

Lazarus, R. S. (1966). Psychological stress and the coping process. McGraw Hill.

Lazarus, R. S., \& Folkman, S. (1984). Stress, appraisal, and coping. Springer. 
Leiter, M. P., Day, A., \& Price, L. (2015). Attachment styles at work: Measurement, collegial relationships, and burnout. Burnout Research, 2(1), 25-35. https://doi.org/10.1016/j.burn.2015.02.003

Lincoln, K. D. (2000). Social support, negative social interactions, and psychological well-being. Social Service Review, 74(2), 231-252. https://doi.org/10.1086/514478

Liu, B. S., \& Rook, K. S. (2013). Emotional and social loneliness in later life: Associations with positive versus negative social exchanges. Journal of Social and Personal Relationships, 3o(6), 813-832. https://doi.org/10.1177/0265407512471809

Lucas, R. E., Diener, E., \& Suh, E. (1996). Discriminant validity of well-being measures. Journal of Personality and Social Psychology, 71(3), 616-628. https://doi.org/10.1037/0022-3514.71.3.616

Ma, C. Q., \& Huebner, E. S. (2008). Attachment relationships and adolescents' life satisfaction: Some relationships matter more to girls than boys. Psychology in the Schools, 45(2), 177-190. https://doi.org/10.1002/pits.20288

Malecki, C. K., \& Demaray, M. K. (2003). What type of support do they need? Investigating student adjustment as related to emotional, informational, appraisal, and instrumental support. School Psychology Quarterly, 18(3), 231-251. https://doi.org/10.1521/scpq.18.3.231.22576

Mattanah, J. F., Ayers, J. F., Brand, B. L., Brooks, L. J., Quimby, J. L., \& McNary, S. W. (2010). A social support intervention to ease the college transition: Exploring main effects and moderators. Journal of College Student Development, 51(1), 93-108. https://doi.org/10.1353/csd.0.0116

Mattanah, J. F., Hancock, G. R., \& Brand, B. L. (2004). Parental attachment, separation-individuation, and college student adjustment: A structural equation analysis of mediational effects. Journal of Counseling Psychology, 51(2), 213-225. https://doi.org/10.1037/0022-0167.51.2.213

Mikulincer, M., \& Florian, V. (1995). Appraisal of and coping with a real-life stressful situation: The contribution of attachment styles. Personality and Social Psychology Bulletin, 21(4), 406-414. https://doi.org/10.1177/0146167295214011

Miller, D. (2007). National responsibility and global justice. Oxford University Press.

Moksnes, U. K., \& Espnes, G. A. (2013). Self-esteem and life satisfaction in adolescents-Gender and age as potential moderators. Quality of Life Research, 22(10), 2921-2928. https://doi.org/10.1007/s11136013-0427-4

Moller, N. P., Fouladi, R. T., McCarthy, C. J., \& Hatch, K. D. (2003). Relationship of attachment and social support to college students' adjustment following a relationship breakup. Journal of Counseling \& Development, 81(3), 354-369. https://doi.org/10.1002/j.1556-6678.2003.tbo0262.x

Morelli, S. A., Lee, I. A., Arnn, M. E., \& Zaki, J. (2015). Emotional and instrumental support provision interact to predict well-being. Emotion, 15(4), 484-493. https://doi.org/10.1037/emoo000084

Newsom, J. T., Nishishiba, M., Morgan, D. L., Rook, K. S. (2003). The relative importance of three domains of positive and negative social exchanges: A longitudinal model with comparable measures. Psychology and Aging, 18, 746-754. https://doi.org/10.1037/0882-7974.18.4.746

Newsom, J. T., Rook, K. S., Nishishiba, M., Sorkin, D. H., \& Mahan, T. L. (2005). Understanding the relative importance of positive and negative social exchanges: Examining specific domains and appraisals. The Journals of Gerontology Series B: Psychological Sciences and Social Sciences, 6o(6), P304P312. https://doi.org/10.1093/geronb/60.6.P304

Newsom, J. T., \& Schulz, R. (1996). Social support as a mediator in the relation between functional status and quality of life in older adults. Psychology and Aging, 11(1), 34-44. https://doi.org/10.1037/08827974.11.1.34 
Nickerson, A. B., \& Nagle, R. J. (2005). Parent and peer attachment in late childhood and early adolescence. The Journal of Early Adolescence, 25(2), 223-249.

https://doi.org/10.1177/0272431604274174

Ognibene, T. C., \& Collins, N. L. (1998). Adult attachment styles, perceived social support and coping strategies. Journal of Social and Personal Relationships, 15(3), 323-345. https://doi.org/10.1177/0265407598153002

Oh, H. J., Ozkaya, E., \& LaRose, R. (2014). How does online social networking enhance life satisfaction? The relationships among online supportive interaction, affect, perceived social support, sense of community, and life satisfaction. Computers in Human Behavior, 30, 69-78. https://doi.org/10.1016/j.chb.2013.07.053

Okun, M. A., \& Keith, V. M. (1998). Effects of positive and negative social exchanges with various sources on depressive symptoms in younger and older adults. The Journals of Gerontology Series B: Psychological Sciences and Social Sciences, 53(1), 4-20. https://doi.org/10.1093/geronb/53B.1.P4

Oswald, D. L., \& Clark, E. M. (2003). Best friends forever?: High school best friendships and the transition to college. Personal relationships, 1O(2), 187-196. https://doi.org/10.1111/1475-6811.00045

Oxman, T. E., Berkman, L. F., Kasl, S., Freeman, D. H., \& Barrett, J. (1992). Social support and depressive symptoms in the elderly. American Journal of Epidemiology, 135, 356-368. https://doi.org/10.1093/oxfordjournals.aje.a116297

Pagel, M. D., Erdly, W. W., \& Becker, J. (1987). Social networks: We get by with (and in spite of) a little help from our friends. Journal of Personality and Social Psychology, 53(4), 793-804. https://doi.org/10.1037/0022-3514.53.4.793

Penninx, B. W., Guralnik, J. M., Ferrucci, L., Simonsick, E. M., Deeg, D. J., \& Wallace, R. B. (1998). Depressive symptoms and physical decline in community-dwelling older persons. JAMA, 279(21), 1720-1726. https://doi.org/10.1001/jama.279.21.1720

Pietromonaco, P. R., \& Barrett, L. F. (1997). Working models of attachment and daily social interactions. Journal of Personality and Social Psychology, 73(6), 1409. https://doi.org/10.1037/00223514.73.6.1409

Pratt, M., Hunsberger, B., Pancer, S., Alisat, S., Bowers, C., Mackey, K., et al. (2000). Facilitating the transition to university: Evaluation of a social support discussion intervention program. Journal of College Student Development, 41, 427-441.

Priel, B., \& Shamai, D. (1995). Attachment style and perceived social support: Effects on affect regulation. Personality and Individual Differences, 19(2), 235-241. https://doi.org/10.1016/01918869(95)91936-T

Ratelle, C. F., Simard, K., \& Guay, F. (2013). University students' subjective well-being: The role of autonomy support from parents, friends, and the romantic partner. Journal of Happiness Studies, 14(3), 893910. https://doi.org/10.1007/s10902-012-9360-4

Rayle, A. D., \& Chung, K. Y. (2007). Revisiting first-year college students' mattering: Social support, academic stress, and the mattering experience. Journal of College Student Retention: Research, Theory \& Practice, 9(1), 21-37.

Reblin, M., \& Uchino, B. N. (2008). Social and emotional support and its implication for health. Current Opinion in Psychiatry, 21(2), 201-205. https://doi.org/10.1097/YCO.obo13e3282f3ad89

Reis, H. T., \& Wheeler, L. (1991). Studying social interaction with the Rochester Interaction Record. In M. P. Zanna (Ed.), Advances in Experimental Social Psychology, 24, 269-318. Academic Press. 
Rook, K. S. (1984). The negative side of social interaction: Impact on psychological well-being. Journal of Personality and Social Psychology, 46, 1097-1108. https://doi.org/10.1037/0022-3514.46.5.1097

Rook, K. S. (1987). Social support versus companionship: Effects on life stress, loneliness, and evaluations by others. Journal of Personality and Social Psychology, 52(6), 1132-1147. https://doi.org/10.1037/0022-3514.52.6.1132

Rook, K. S. (1990). Parallels in the study of social support and social strain. Journal of Social and Clinical Psychology, 9, 118-132. https://doi.org/10.1521/jscp.1990.9.1.118

Rook, K. S. (1998). Investigating the positive and negative sides of personal relationships: Through a glass darkly? In B. H. Spitzberg \& W. R. Cupach (Eds.), The dark side of close relationships (pp. 369-393). Erlbaum.

Rook, K. S. (2001). Emotional health and positive versus negative social exchanges: A daily diary analysis. Applied Developmental Science, 5(2), 86-97. https://doi.org/10.1207/S1532480XADS0502_4

Scholte, R. H., Van Lieshout, C. F., \& Van Aken, M. A. (2001). Perceived relational support in adolescence: Dimensions, configurations, and adolescent adjustment. Journal of Research on Adolescence, 11(1), 71-94. https://doi.org/10.1111/1532-7795.00004

Schuster, T. L., Kessler, R. C., \& Aseltine, R. H. (1990). Supportive interactions, negative interactions, and depressed mood. American Journal of Community Psychology, 18(3), 423-438. https://doi.org/10.1007/BFo0938116

Shulman, S., \& Ben-Artzi, E. (2003). Age-related differences in the transition from adolescence to adulthood and links with family relationships. Journal of Adult Development, 1O(4), 217-226. https://doi.org/10.1023/A:1026006025155

Sibley, C. G., Fischer, R., \& Liu, J. H. (2005). Reliability and validity of the Revised Experiences in Close Relationships (ECR-R) self-report measure of adult romantic attachment. Personality and Social Psychology Bulletin, 31(11), 1524-1536. https://doi.org/10.1177/0146167205276865

Simpson, D. B., \& Burnett, D. (2019). Commuters versus residents: The effects of living arrangement and student engagement on academic performance. Journal of College Student Retention: Research, Theory \& Practice, 21(3), 286-304. https://doi.org/10.1177/1521025117707516

Suldo, S. M., Riley, K. N., \& Shaffer, E. J. (2006). Academic correlates of children and adolescents' life satisfaction. School Psychology International, 27(5), 567-582. https://doi.org/10.1177/0143034306073411

Thoits, P (1995). Stress, coping, and social support processes: Where are we? What next? Journal of Health and Social Behavior, 35, 53-79. https://doi.org/10.2307/2626957

Uchino, B. N. (2009). Understanding the links between social support and physical health: A life-span perspective with emphasis on the separability of perceived and received support. Perspectives on Psychological Science, 4(3), 236-255. https://doi.org/10.1111/j.1745-6924.2009.01122.x

Uchino, B. N. (2006). Social support and health: A review of physiological processes potentially underlying links to disease outcomes. Journal of Behavioral Medicine, 29(4), 377-387. https://doi.org/10.1007/s10865-006-9056-5

Umberson, D., \& Montez, J. (2010). Social relationships and health: A flashpoint for health policy. Journal of Health and Social Behavior, 51(1_suppl), S54-S66. https://doi.org/10.1177/0022146510383501

Walen, H. R., \& Lachman, M. E. (2000). Social support and strain from partner, family, and friends: Costs and benefits for men and women in adulthood. Journal of Social and Personal Relationships, 17(1), 5-30. https://doi.org/10.1177/0265407500171001 
Wei, M., Liao, K. Y. H., Ku, T. Y., \& Shaffer, P. A. (2011). Attachment, self-compassion, empathy, and subjective well-being among college students and community adults. Journal of Personality, 79(1), 191-221. https://doi.org/10.1111/j.1467-6494.2010.00677.x

West, M., Livesley, W. J., Reiffer, L., \& Sheldon, A. (1986). The place of attachment in the life events model of stress and illness. Canadian Journal of Psychiatry, 31, 202-207. https://doi.org/10.1177/070674378603100304

Wilkinson, R. B. (2011). Measuring attachment dimensions in adolescents: Development and validation of the Experiences in Close Relationships-Revised-General Short Form. Journal of Relationships Research, 2(1), 53-62. https://doi.org/10.1375/jrr.2.1.53

Wills, T. A., \& Ainette, M. C. (2012). Social networks and social support. In A. Baum, T. A. Revenson, \& J. Singer (Eds.), Handbook of health psychology (pp. 465-492). Psychology Press. journal focusing on theoretically-based research that addresses contemporary national and international issues. $J S B H S$ articles include peer-reviewed research reports, brief reports, comprehensive literature reviews, books reviews, and student research. 